\title{
Assessing the Safety of Day Care Thyroidectomy in Indian Population: A Prospective Study
}

\author{
Devender Singh ${ }^{1}$, Yashwant S Rathore ${ }^{2}$, Sandeep Jain ${ }^{3}$, Gaurav Joshi ${ }^{4}$, Gurpremjit Singh ${ }^{5}$, Vitish Singla ${ }^{6}$
}

\begin{abstract}
In the era of improved surgical and anesthetic techniques, the day care thyroidectomies have been found to be associated with improved patient performance and convenience, and reduced exposure to hospital-acquired complications leading to reduced overall morbidity. However, these benefits are still questioned due to certain postoperative complications.

Aim: The aim of this study was to observe the follow-up of patients undergoing day care thyroidectomy operations and determine the safety of day care thyroidectomy in Indian population.

Materials and methods: This was a single center, in-hospital, prospective, uncontrolled observational study. A total number of 50 patients were included in the study. The study was conducted in the Department of Surgical Disciplines, All India Institute of Medical Sciences (AllMS), New Delhi, with the duration from January 2016 to September 2017. After assessing the inclusion and exclusion criteria, proper workup and taking informed written consent, patients were taken up for day care thyroidectomy. These patients were observed and followed up on day 0 , day 7 , and day 30 postoperatively for any thyroidectomy-related complications.

Results: The mean age for the study population was $35.6 \pm 11.27$ years (18-60 years). Out of 50, 35 (70\%) were females and the female-tomale ratio was $2.25: 1$. Out of $50(2 \%), 1$ patient had a postoperative hematoma formation, $2 / 50(4 \%)$ patients had postoperative transient hypocalcaemia, and 1/50 (2\%) patient had postoperative voice changes.

Conclusion: This study showed that day care thyroidectomy is a safe and feasible approach with a supporting caregiver and accessible emergency services.

Clinical significance: In a developing country like India with limited resources, day care thyroidectomy can provide a safe and better costeffective alternative to the routinely practiced in-patient thyroidectomy.

Keywords: Postoperative hypocalcemia, Thyroid, Thyroidectomy.

World Journal of Endocrine Surgery (2020): 10.5005/jp-journals-10002-1272
\end{abstract}

\section{INTRODUCTION}

In this era of improved surgical and anesthetic techniques, a number of day care surgeries have been increased tremendously. A day care surgery is defined as admission and discharge of a patient on the same day. The benefits of day care thyroidectomy are improved patient performance and convenience, and reduced exposure to hospital-acquired complications leading to reduced overall morbidity. However, these benefits are still questioned due to certain postoperative complications. The primary complications related to day care thyroidectomies that challenge day care management are hematoma or bleeding, airway compromise, hypocalcemia, and voice changes due to recurrent laryngeal nerve (RLN) palsy. The purpose of this study was to assess the safety of day care thyroidectomy operations in Indian population.

\section{Materials and Methods}

This was a single institution, in-hospital, prospective, uncontrolled observational study. The patients who presented to surgery outpatient department, AlIMS, New Delhi, were recruited in the study. Ethical approval was obtained from the AlIMS Ethics Committee. The study was carried out in the Department of Surgical Disciplines and Department of Pathology, AlIMS, New Delhi, from January 2016 to September 2017. The number of patients recruited in the study was 50 . These patients were observed and followed up at postoperative day 0 , day 7 , and day 30 to assess for any postoperative complications. \begin{tabular}{l}
\hline${ }^{1-6}$ Department of Surgical Disciplines, All India Institute of Medical \\
Sciences, New Delhi, India \\
Corresponding Author: Yashwant S Rathore, Department of Surgical \\
Disciplines, All India Institute of Medical Sciences, New Delhi, India, \\
Phone: +91 9911337726, e-mail: dryashvant.r@gmail.com \\
How to cite this article: Singh D, Rathore YS, Jain S, et al. Assessing the \\
Safety of Day Care Thyroidectomy in Indian Population: A Prospective \\
Study. World J Endoc Surg 2020;12(1):14-17. \\
Source of support: All India Institute of Medical Sciences, New Delhi, \\
India \\
Conflict of interest: None
\end{tabular}

The inclusion criteria were patient of age 18-60 years who gave informed written consent for the study, a patient seen in preadmission assessment clinic (by an anesthesiologist) and cleared for surgery, euthyroid patients, cases of a solitary thyroid nodule, multinodular goiter, and carcinoma thyroid. Exclusion criteria were patients with features of hyperthyroidism/hypothyroidism, patients with retrosternal or intrathoracic extension of the thyroid, patient unfit for general anesthesia, and patients who were in need of thyroidectomy with modified radical neck dissection.

All patients underwent a comprehensive multidisciplinary endocrine evaluation preoperatively, which included preoperative indirect laryngoscopy to rule out any vocal cord deformity, routine ultrasonography (USG) neck to evaluate the thyroid swelling, endocrinology evaluation for euthyroid /hyperthyroid assessment,

(c) The Author(s). 2020 Open Access This article is distributed under the terms of the Creative Commons Attribution 4.0 International License (https://creativecommons. org/licenses/by-nc/4.0/), which permits unrestricted use, distribution, and non-commercial reproduction in any medium, provided you give appropriate credit to the original author(s) and the source, provide a link to the Creative Commons license, and indicate if changes were made. The Creative Commons Public Domain Dedication waiver (http://creativecommons.org/publicdomain/zero/1.0/) applies to the data made available in this article, unless otherwise stated. 


\begin{tabular}{ll} 
Table 1: Criteria for patient discharge \\
\hline 1 & $\begin{array}{l}\text { The patient was awake and alert and oriented about to } \\
\text { commands. }\end{array}$ \\
2 & $\begin{array}{l}\text { The patient was able to ambulate with/ without minimal } \\
\text { assistance. }\end{array}$ \\
3 & $\begin{array}{l}\text { There were no complaints of nausea, vomiting, } \\
\text { respiratory distress, bleeding or neck swelling. }\end{array}$ \\
4 & $\begin{array}{l}\text { The patient was discharged with a responsible family } \\
\text { adult member. }\end{array}$ \\
5 & $\begin{array}{l}\text { Modified PA-DSS was } 9 \text { or }>9 \\
6\end{array}$ \\
& $\mathrm{SpO}_{2}$ is $>95 \%$.
\end{tabular}

and preoperative fine needle aspiration cytology (FNAC) of thyroid swelling. They were reported as per the Bethesda reporting system.

All patients were provided with a patient information leaflet and were counseled regarding the concept of day care thyroidectomy, the benefits of day care thyroidectomy, the risks of day care thyroidectomy, the need for at least 30 days follow-up, the need to stay at 20-30-minute travel time distance to the hospital.

Complete history and physical examination were performed after the admission of the patient. The decision for surgical procedures was made on the basis of clinical examinations, radiological findings of USG neck, and pathological findings of FNAC. Technique of different surgical procedures employed were hemithyroidectomy, total thyroidectomy, near-total thyroidectomy, and completion thyroidectomy. No drain was placed after any of the surgical procedures. Patient was extubated with the help of direct video laryngoscopy for documentation for any vocal cord dysfunction.

In the immediate postoperative period, the patients were kept in the recovery room. For the initial 6 hours, the patients were kept nil per orally, on intravenous fluids. The patients were shifted to the ward after a proper evaluation and clearance from the expert anesthetic. The patients were started on oral liquids after 6 hours of the postoperative period in the ward. Then patient subsequently introduced on semisolid and solid foods. The patients who underwent total thyroidectomy and completion thyroidectomy were started on prophylactic supplementation of oral calcium and vitamin D for 2 weeks. The further doses were continued only if patients had a clinical suspicion of hypocalcaemia. On discharge, all patients were prescribed oral analgesics for pain management. The criteria for discharging the patients are given in Table 1.

Patients were examined and assessed at postoperative days 0,7 , and 30 for various postthyroidectomy complications. Postoperative bleeding and hematoma formation were assessed as if the patients had any recent onset neck swelling, bleeding from neck incision, or any compressive symptoms. Compressive symptoms like dyspnea, dysphonia, stridor, or choking were also assessed. Postoperative voice changes were assessed subjectively as if the patients had any hoarseness of voice or if there was any change in intensity or pitch of the voice. Postoperative hypocalcemia was assessed as if the patients had paresthesia in extremities or any tingling sensations in extremities.

\section{Results}

Out of the 50 patients, 35 (70\%) were females and the female-tomale ratio was 2.25:1.
Table 2: Preoperative diagnosis and the procedure performed in the study population

\begin{tabular}{|c|c|c|c|}
\hline S. no. & $\begin{array}{l}\text { Preoperative } \\
\text { diagnosis }\end{array}$ & $\begin{array}{l}\text { Total number } \\
(n=50)\end{array}$ & Operation performed \\
\hline 1 & $\begin{array}{l}\text { Solitary thyroid } \\
\text { nodule }\end{array}$ & $32(64 \%)$ & Hemithyroidectomy \\
\hline 2 & Multinodular goiter & $3(6 \%)$ & $\begin{array}{l}\text { Near total } \\
\text { thyroidectomy }\end{array}$ \\
\hline 3 & $\begin{array}{l}\text { Papillary thyroid } \\
\text { carcinoma }\end{array}$ & $12(24 \%)$ & Total thyroidectomy \\
\hline 4 & $\begin{array}{l}\text { Papillary thyroid } \\
\text { carcinoma status } \\
\text { posthemithyroid- } \\
\text { ectomy }\end{array}$ & $3(6 \%)$ & $\begin{array}{l}\text { Completion } \\
\text { thyroidectomy }\end{array}$ \\
\hline
\end{tabular}

Table 3: Postoperative complications found in study population $(n=50)$

\begin{tabular}{lllll}
\hline Complication & Day 0 & $\begin{array}{l}\text { After } \\
\text { discharge }\end{array}$ & Day 7 & Day 30 \\
\hline $\begin{array}{l}\text { Postoperative hematoma } \\
\text { Postoperative respiratory }\end{array}$ & - & 1 & - & - \\
$\begin{array}{l}\text { difficulty } \\
\text { Voice changes }\end{array}$ & 18 & 18 & - & - \\
Hypocalcemia & - & - & 4 & 1 \\
\hline
\end{tabular}

Mean age for the study population was $35.6 \pm 11.27$ years (18-60 years). Preoperative diagnosis and procedure performed in the study population are given in Table 2.

The various complications in the study population are summarized in Table 3.

Only one patient, 28 years old male, had a postoperative hematoma formation and respiratory depression. The patient was discharged on postoperative day 0 after optimal postoperative recovery. However, he presented to emergency with swelling at the surgical site and respiratory distress. The surgical site was immediately reexplored and airway restoration was achieved. Clotted blood was evacuated. There were areas of minor ooze from strap muscle edges. Hemostasis achieved, and the drain was placed. Then after, the patient had an uneventful recovery. The patient also had an uneventful follow-up on postoperative days 7 and 30 . Hence, the frequency for hematoma formation was $1 / 50$ (2\%).

Postoperative voice changes were assessed subjectively. Out of $50,18(36 \%)$ complained of postoperative voice changes on day 0 . Out of 50, 17 (34\%) patients had a complete recovery of normal voice by day 30 , but $1 / 50$ (2\%) patient continued to have same voice changes as postoperatively without a sign of improvement even at day 30. Therefore, the frequency of persistent voice change was $2 \%$ in this study population.

In the study population, two patients who underwent total thyroidectomy and completion thyroidectomy, respectively, complained of hypocalcemia symptoms (perioral tingling and numbness) on day 7 postoperatively on follow-up, for which serum calcium was measured and found to be between $8 \mathrm{mg} / \mathrm{dL}$ and $9 \mathrm{mg} /$ $\mathrm{dL}$. Both patients were managed by increasing their doses for oral calcium and vitamin D. On day 30 postoperatively, both patients had a complete recovery of the hypocalcemia symptoms.

\section{Discussion}

In the past two decades, there has been a shift in the momentum as the increasing number of surgeries, which were previously preferred 
to be managed as in-patient settings, are now preferably managed as an outpatient approach. Thyroid surgeries can be performed in the majority of cases without the need for hospitalization after recovery from anesthesia. Both improved surgical and anesthesia techniques have led to improved patient management and facilitated the day care thyroidectomies.

Undoubtfully, day care surgeries have advantages for both patients and surgeons as they are convenient, safe, and costeffective. Still, thyroid surgeries are associated with a small risk of specific life-threatening complications, principally airway obstruction from hemorrhage, RLN palsy, and tetany from severe hypocalcemia, which should be closely monitored.

A postoperative hematoma is a potentially life-threatening complication after thyroidectomy. The incidence of postoperative hematoma is $0.9-2.1 .^{1-8}$ It is also the leading cause of mortality in the early postoperative period following thyroidectomy. In recent literature, Synder et al. ${ }^{9}$ in his study of 1,064 day care thyroidectomies showed that only $0.2 \%$ of patients had hematoma formation. ${ }^{9}$ Similarly, Inabnet et al. ${ }^{10}(n=180)$ showed a rate of $0.4 \%$ hematoma formation. ${ }^{10}$ The highest incidence of hematoma formation was reported in Terris et al. ${ }^{11}(n=52)$, which had shown hematoma formation rates of $1.9 \%,{ }^{11}$ whereas Sklar et al. ${ }^{12}$ and Houlton et al. ${ }^{13}$ did not have any complications regarding hematoma formation in their studies. ${ }^{12,13}$ In this study, only one patient, 28 years. old male, had postoperative hematoma formation and respiratory depression. So, our frequency for hematoma formation was $2 \%$.

Hypocalcemia is a common complication following total thyroidectomy and completion thyroidectomy rather than a hemithyroidectomy. The common cause for hypocalcemia is an injury to parathyroid gland vascular supply. The postoperative hypocalcemia may be transient or permanent. Fortunately, transient hypocalcemia is more common and it responds to oral calcium and vitamin D supplementation. Hypocalcemia may manifest as mild (paresthesia around lips, mouth, hands, and feet) or moderate (muscle twitches or frank cramps) to severe (trismus or tetany). Synder et al. in his 1,064 study patients, out of which 58 were total thyroidectomies, showed hypocalcemia in $5.2 \%$ patients. ${ }^{9}$ Seybt et al. ${ }^{14}$ showed a $1.9 \%$ incidence in 208 outpatient thyroidectomy patients, out of which 38 underwent total thyroidectomy. ${ }^{14}$ However, Houlton et al. ${ }^{13}(n=95)$ showed the absence of transient hypocalcemia in a study in spite of all patients underwent total thyroidectomy. ${ }^{13}$ This shows that meticulous dissection with the preservation of parathyroid glands and prophylactic oral calcium may prevent postoperative hypocalcemia even in total thyroidectomy patients. In this study population, only two patients had hypocalcemia symptoms. Both of the patients had undergone total thyroidectomy and completion thyroidectomy, respectively, and had hypocalcemia symptoms at postoperative day 7 of follow-up. The dosages of oral calcium were increased, and following this, the patients had a complete recovery from these symptoms. Overall, the frequency of transient hypocalcemia in our population was $4 \%$. In this study population, all patients who underwent total thyroidectomy and completion thyroidectomy were prescribed the prophylactic oral calcium and vitamin D supplementation as a standard protocol. This may be the explanation for the low incidence of the transient hypocalcemia at an immediate postoperative period in our study population. Hence, this shows that the prophylactic supplementation of oral calcium with vitamin D may be advised in total and completion thyroidectomies done in a day care setting.
Postoperative voice change is a well-recognized complication of thyroidectomy. Voice changes mostly present as hoarseness of voice. Transient hoarseness of voice may be due to vocal cord edema because of endotracheal intubation or vocal cord paresis due to nerve injury. Persistent hoarseness of voice may be due to vocal cord dysfunction due to nerve injury. In literature, studies have also shown the higher incidence of temporary voice changes and transient nerve paresis. One of the recent meta-analyses of five studies with 1,717 cases of outpatient thyroidectomy showed the incidence of temporary RLN palsy $0-4 \%$. Similarly, a rate of $0-2 \%$ permanent RLN palsy was reported in ten studies with 2,505 cases. ${ }^{15}$ Snyder et al. ${ }^{9}(n=1,063)$ showed a temporary RLN palsy frequency of $3.7 \%$ (39 patients) and permanent nerve injury rate $0.4 \%$ (4 patients). ${ }^{1}$ Mazeh et al. ${ }^{16}(n=87)$ and Sahmkow et al. ${ }^{17}(n=171)$ showed temporary RLN nerve palsy rates of $2 \%$ and $1 \%$, respectively. However, both the studies did not show any permanent nerve injury. ${ }^{16,17}$ In this study population, 18 patients complained of postoperative voice changes on day 0 , out of which 16 patients had a husky voice and 2 patients complained of reduced intensity of voice. Subsequently, 9 patients showed improvement in voice at postoperative day 7 , whereas 5 patients had complete recovery of the voice symptoms. Four patients continued to have the voice changes at postoperative day 7. One patient continued to have same voice changes as postoperatively without a sign of improvement even at day 30. The patient was evaluated by indirect laryngoscopy and found to have normal vocal cords. Hence, at postoperative day 30 , the frequency of voice changes was $2 \%$. As most of the immediate and early postoperative voice changes were attributed to postintubation vocal cords edema, most of the patients with voice changes had either improvement or complete resolution of the symptoms in the follow-up of 30 days. So, on postoperative day 30 , the frequency of voice changes was $2 \%$. None of the patients had stridor, choking, or aspiration due to nerve palsy. Similarly, none of the patients had bilateral nerve palsy or unilateral nerve palsy on immediate postextubation direct laryngoscopy. Overall, this can be emphasized that postoperative voice changes in day care thyroidectomy do not usually prohibit the discharge of the patient.

Hence, a low rate of complications suggests that thyroid surgery can be performed as a day care procedure with acceptable complication rates. Most of the day care thyroidectomies can be performed as per established standard protocols, but if lifethreatening complications like hematoma formation or respiratory depression occurs, patient must be managed immediately in inpatient setting.

\section{Conclusion}

It was found that day care thyroidectomy offers comparable postoperative outcomes in terms of standard care thyroidectomy. With a supportive caregiver and accessible emergency services, day care thyroidectomy is feasible with minimum complications.

\section{Clinical Significance}

In a developing country like India with limited resources, day care thyroidectomy can provide a safe and better cost-effective alternative to the routinely practiced in-patient thyroidectomy.

\section{ACKNowledgment}

Research was approved by ethics committee. 


\section{References}

1. Terris DJ, Snyder S, Carneiro-Pla D, et al. American thyroid association statement on outpatient thyroidectomy. Thyroid 2013;23(10): 1193-1202. DOI: 10.1089/thy.2013.0049.

2. Diongi G, Rovera F, Carrafielo G, et al. Ambulatory thyroid surgery: need for stricter patient selection criteria. Int J Surg 2008;6(Suppl 1): S19-S21.

3. Promberger R, Ott J, Kober F, et al. Risk factors for post-operative bleeding after thyroid surgery. Br J Surg 2012;99(3):373-379. DOI: 10.1002/bjs.7824.

4. Leyre $P$, Desurmont $T$, Lacoste $L$, et al. Does the risk of compressive hematoma after thyroidectomy authorize 1-day surgery? Langenbecks Arch of Surg 2008;393(5):733-737. DOI: 10.1007/s00423-008-0362-y.

5. Burkey SH, van Heerden JA, Thompson GB, et al. Reexploration for symptomatic hematomas after cervical exploration. Surgery 2001;130(6):914-920. DOI: 10.1067/msy.2001.118384.

6. Weiss A, Lee KC, Brumund KT, et al. Risk factors for hematoma after thyroidectomy: results from the nationwide inpatient sample. Surgery 2014;156(2):399-404. DOI: 10.1016/j.surg.2014.03.015.

7. Trottier DC, Barron P, Moonje V, et al. Outpatient thyroid surgery: should patients be discharged on the day of their procedures? Can J Surg 2009;52(3):182-186.

8. Doran HE, England J, Palazzo F, et al. Questionable safety of thyroid surgery with same day discharge. Ann R Coll Surg Engl 2012;94(8):543-547. DOI: 10.1308/003588412X13373405384576.

9. Snyder SK, Hamid KS, Roberson CR, et al. Outpatient thyroidectomy is safe and reasonable: experience with more than 1,000 planned outpatient procedures. J Am Coll Surg 2010;210(5):575-582, 582-584 10.1016/j.jamcollsurg.2009.12.037.

10. Inabnet WB, Shifrin A, Ahmed L, et al. Safety of same day discharge in patients undergoing sutureless thyroidectomy: a comparison of local and general anesthesia. Thyroid 2008;18(1):57-61. DOI: 10.1089/ thy.2007.0148.

11. Terris DJ, Moister B, Seybt MW, et al. Outpatient thyroid surgery is safe and desirable. Otolaryngol Head Neck Surg 2007;136(4):556-559. DOI: 10.1016/j.otohns.2006.09.024.

12. Sklar M, Ali MJ, Solomon P. Outpatient thyroid surgery in a Toronto community hospital. J Otolaryngol Head Neck Surg 2011;40(6): 458-461.

13. Houlton JJ, Pechter W, Steward DL. PACU PTH facilitates safe outpatient total thyroidectomy. Otolaryngol Head Neck Surg 2011;144(1):43-47. DOI: 10.1177/0194599810390453.

14. Seybt MW, Terris DJ. Outpatient thyroidectomy: experience in over 200 patients. Laryngoscope 2010;120(5):959-963. DOI: 10.1002/ lary.20866.

15. Khadra H, Mohamed S, Hauch A, et al. Safety of same-day thyroidectomy: meta-analysis and systematic review. Gland Surg 2017;6(4):292-301. DOI: 10.21037/gs.2017.01.05.

16. Mazeh $\mathrm{H}$, Khan Q, Schneider DF, et al. Same-day thyroidectomy program: eligibility and safety evaluation. Surgery 2012;152(6): 1133-1141. DOI: 10.1016/j.surg.2012.08.033.

17. Sahmkow Sl, Audet N, Nadeau S, et al. Outpatient thyroidectomy: safety and patient's satisfaction. J Otolaryngol Head Neck Surg 2012;41(Suppl 1):S1-S12. 